\title{
The Most Popular Chemical Categories of NPS in Four Leading Countries of the Developed World: An Integrative Analysis of Trends Databases, Surface Web, and the Deep Web
}

\author{
Ahmed Al-Imam ${ }^{1,2} \&$ Ban A. AbdulMajeed ${ }^{3}$ \\ ${ }^{1}$ Department of Postgraduate Medicine, School of Life and Medical Sciences, University of Hertfordshire, United \\ Kingdom \\ ${ }^{2}$ Department of Anatomy and Cellular Biology, Faculty of Medicine, University of Baghdad, Iraq \\ ${ }^{3}$ Department of Pathology and Forensic Medicine, College of Medicine, Al-Nahrain University, Iraq \\ Correspondence: Dr Ahmed Al-Imam, House 18/5, Al-Akhtal Street, District 318, Al-Adhamyia, 10053, Baghdad, \\ Iraq. E-mail: tesla1452@gmail.com; a.m.al-imam@herts.ac.uk
}

Received: July 25, 2017 Accepted: August 17, 2017 Online Published: September 18, 2017

doi:10.5539/gjhs.v9n11p27 URL: https://doi.org/10.5539/gjhs.v9n11p27

\begin{abstract}
Background: New psychoactive substances are very diverse; hundreds exist today. Several schemes exist to categorise them; NPS can be classified into Cannabinoids and Cannabimimetics (1), Phenethylamines (2), Cathinones (3), Tryptamines (4), Piperazines (5), Pipradrol derivatives (6), and miscellaneous substances (7)

Materials and Methods: Observational analyses via multiple internet snapshots will be carried out on the surface web and the deep web. The analyses will be hierarchical and integrative to infer the most popular categories of NPS based on the attentiveness (interest) of web users.

Results: Analysis of Google Trends from 2012 to the end of 2016, shows that interest in cannabinoids was the highest $(98 \%)$, while all other chemical categories of NPS summed up to a tiny fragment $(2 \%)$. The trends were highly oscillating over the years and shooting up during holiday seasons. Geo-mapping and localisation of the Middle East were not possible (not allowed) via Google Trends, while trends were attributed to four major leading countries of the developed world; US (35\%), UK (17\%), Canada (26\%), and Australia (22\%). Cannabinoids and stimulants were also found to be the most popular on the darknet.

Conclusion: A novel method is proposed in this study; it has been carried out to provide an updated extrapolation on the most favoured chemical categories of NPS. This method is based on a combinatory examination at multiple levels of the surface web and the deep web. Furthermore, this method when potentially combined with data mining tools should provide unprecedented real-time analyses of high quality.
\end{abstract}

Keywords: NPS classification, geographic mapping, cannabis, cannabinoids, cannabimimetic, phenethylamines, cathinones, tryptamines, piperazines, pipradrol

\section{Background}

Novel (new) psychoactive drugs (NPS), also known as designer drugs, represent an extraordinary neuro-chemical phenomenon of the $21^{\text {st }}$ century; the escalating rise in the NPS spectacle seems to be unparalleled by efforts of researchers, governmental agencies, and regulating bodies combined (Al-Imam et al., 2016; Al-Imam et al., 2017; Rolles et al., 2014; Saniotis, 2010; Tracy et al., 2017). There were numerous attempts to restrict the spread of designer drugs and research chemicals (NPS). However, most of these attempts were somehow limited; it can be deducted that NPS global "industry" is not only driven by money, human desire, greed, and sometimes terrorism and extremism, but also by the booming progress in the field of information and communication technologies (ICT) (Burchardt et al., 2014; Fettweis, 2014; Webster, 2014). All those factors have led to a shift of the NPS commerce towards NPS e-commerce (e-trade) on virtual space of the internet. Later, the advent of the anonymity and the Bitcoin payment system on the deep web, led to a more aggressive and unrestrained spread of these illicit substances (Jha et al., 2014; Lee and Wei, 2016; Reid \& Harrigan, 2013; Van Hout et al., 2013; Van Hout et al., 2014). To this exact moment, the NPS researchers do merely observe rather than being equally effective in intervening to limit this disastrous threat to public health and the global economy. 
Despite all these encountered difficulties, there are still some bright expectations in the horizon; this study will explore the implementation of advanced (inferential) statistics, extra-large databases, data crunching, and the concept of data mining; the latter is also known as knowledge discovery in databases (KDD) (Fan \& Bifet, 2013; Larose, 2014; Wu et al., 2014). To provide an oversimplification of the NPS phenomenon, one must understand the classification (based on chemical categorization or others) for these illicit (or dysregulated) substances. Designer drugs can be categorised based into; Cannabinoids and Cannabimimetics (1), Phenethylamines (2), Cathinones (3), Tryptamines (4), Piperazines (5), Pipradrol derivatives (6), and a miscellaneous category (7); this classification system has been proposed by the European Monitoring Centre for Drugs and Drug Addiction (EMCDDA) in 2012, it was based on 252 reported substances from 1997 to 2012 (Dargan and Wood, 2013; EMCDDA, 2013; Griffiths et al., 2014). In 2012, the EMCDDA estimated that the NPS prevalences were; cannabinoids (26\%) phenethylamines $(20 \%)$, cathinones $(16 \%)$, tryptamines $(11 \%)$, piperazines $(5 \%)$, pipradol derivatives $(2 \%)$, and miscellaneous (20\%) (Dargan \& Wood, 2013).

The best way to understand the general trend for a phenomenon is to study large or extra-large databases; Google Trends database fits this purpose perfectly. This database permits the use of specific keywords in addition to the application of specific filters for time and geographic location. The keywords to be used (in this study) are the same keywords from the classification system of NPS (EMCDDA, 2012); these keywords will be used to derive statistical inferences. The potentials of this technique are very promising; it can also be used as a template for data mining algorithms; the aim is to apprehend the overall trends on the surface web, the popularity of NPS in specific regions of the world, and to test if these trends are compatible with the patterns existing on the deep web, specifically on the e-markets of the darknet (Miranda, 2014; Lederman, 2016; Rudesill et al., 2015).

\section{Materials and Methods}

This study has been ethically approved by the institutional review board (IRB) of the College of Medicine at the University of Baghdad (IRB meeting number 8 , on the $20^{\text {th }}$ of December 2016). This study will analyse the web (surface web) contents in relation to the most popular categories of NPS on the chemical characterizations; the analysis will form the basis for more advanced inferences on the surface web via medical literature databases mainly PubMed/Medline, drug fora, deep web, and the darknet e-marketplace. The aim of this approach to intertwine the interest (or the attentiveness) of web users on the surface web in parallel to the most famous categories of NPS on the deep web. The attentiveness of surface web users have been analyzed via Google Trends databases by a series of snapshots (Internet snapshots); these were taken from the $14^{\text {th }}$ to the $18^{\text {th }}$ of February 2017 (Google Trends, 2017). Six keywords representative for each category of NPS were used across Google Trends; these are; Cannabinoids, Phenethylamines, Cathinones, Tryptamines, Piperazines, and Pipradrol.

The analysis, via Google Trends, was done for the period from the exact beginning of 2012 to the definite end of 2016, a whole duration of five (5) years. Hence, this study is observational and longitudinal (retrospective). Filters were used for the purpose of geographic mapping (geo-mapping) in; worldwide (Global), United States (US), United Kingdom (UK), Australia, and Canada. Data from the Middle East or Arabic country were not retrievable due to limitations of the database itself. However, these data were sought after during the global (worldwide) analysis using specific filters and whenever the database allowed it. Similarly, data were not attainable from regions of high population density including China and India. In fact, it seems that China does not permit the use of Google and its related applications (O'Rourke et al., 2007; Stevens, 2015; Thompson, 2006). Therefore, this analytic study was limited to some of the developed western countries. In fact, the "Interest by region" shown by default on Google Trends permitted the data access to four countries only, namely; the US, UK, Canada, and Australia.

The implemented statistical analyses were both descriptive and inferential; statistical tests included the analysis of variance (ANOVA), Student's t-test (paired and independent), and the chi-square test. Significance was considered at an alpha $(\alpha)$ value of 0.05 and a confidence interval of $95 \%(95 \% \mathrm{CI})$. Testing for significance was done; in between the different categories of NPS (1), within the same NPS category over the years for the period 2012-2016 (2), and in between the various geolocations (3).

\section{Results and Discussion}

Google Trends database represents one of the major resources of data from the surface web; the trends database will always be approached first which will be followed by analyses of other components of the surface web including literature databases, then to be followed by reviewing the deep web and the darknet e-marketplace (Figure 1). In relation to Google Trends, there were no data accessible in connection with the Middle East or Arabic countries; Google Trends database enabled an option for geographic mapping (geo-mapping) which allowed a restricted access to data from four countries only; the US, UK, Canada, and Australia (Figure 2). Top 
related queries by surface web users in these countries were; phenethylamine, "tryptamines I have known and loved", synthetic cathinones, and bath salts. Geo-mapping has shown that the US is in the lead (Figure 2) in relation to the attentiveness of surface web users towards categories of NPS; these countries contributed as follows; US (35\%), UK (17\%), Canada (26\%), and Australia (22\%). Interest in cannabinoids was the highest $(98 \%)$, while all other categories of NPS summed up to a tiny fragment (2\%); the majority of the latter fell into the chemical category of cathinones (Figure 3). In the global analysis, despite that synthetic cannabinoids seem to hold a high leverage against other NPS, descriptive statistics are usually inconclusive for the purpose of inference. Hence, a statistical inference was established using ANOVA test was used and it confirmed the existence of a statistically significant difference ( $p$-value $<0.001$ ), at an average (mean value) attentiveness of web users in; Cannabinoids (62.96), Phenethylamines (2.44), Cathinones (3.79), Tryptamines (2.93), Piperazines (1.91), and Pipradrol (1.12). The temporal change (2012-2016) in the trends was not conclusive (highly oscillating), though the highest attentiveness to cannabinoids was recorded on the March 2014 and April 2015 (Figure 4), while the highest interests in cathinones were recorded in May 2012, November 2012, and January 2013.

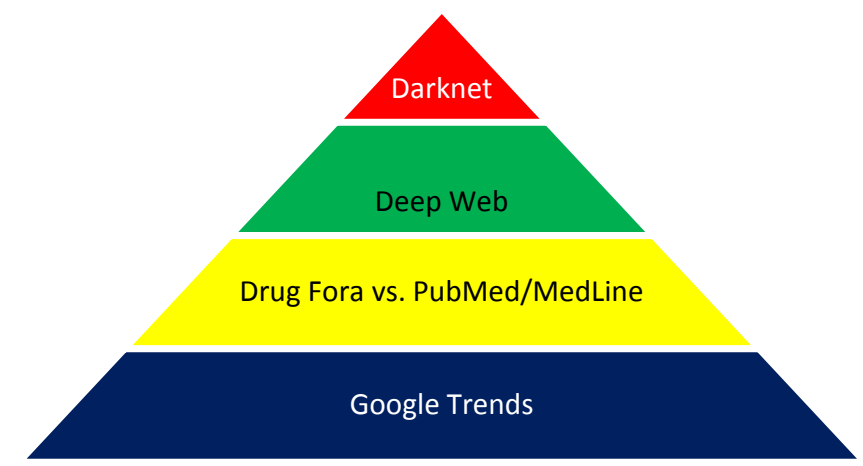

Figure 1. The Hierarchical Analytic Approach for Studying the NPS trends on the Web
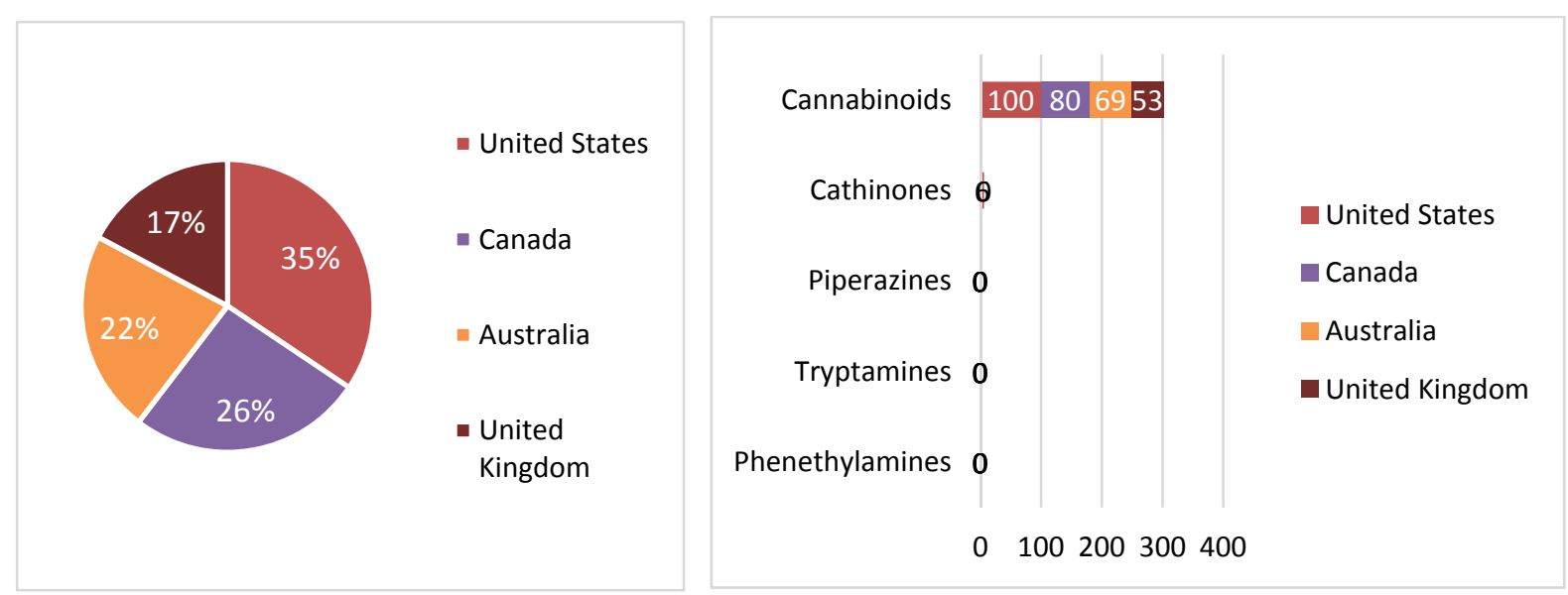

Figure 2. Google Trends Analyses of the Major Chemical Categories of NPS (2012-2016) 


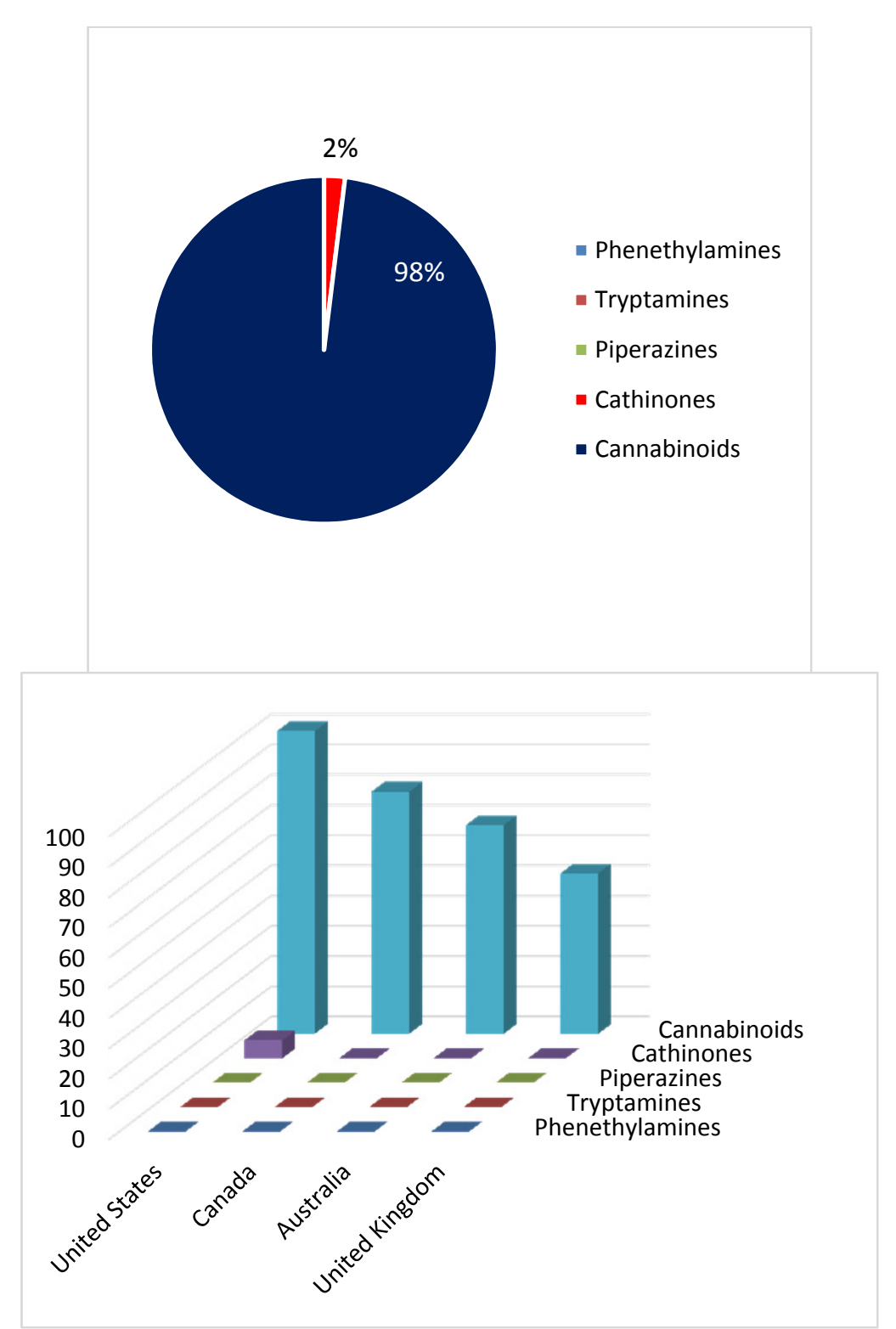

Figure 3. Google Trends Analyses of the Major Chemical Categories of NPS (2012-2016) 


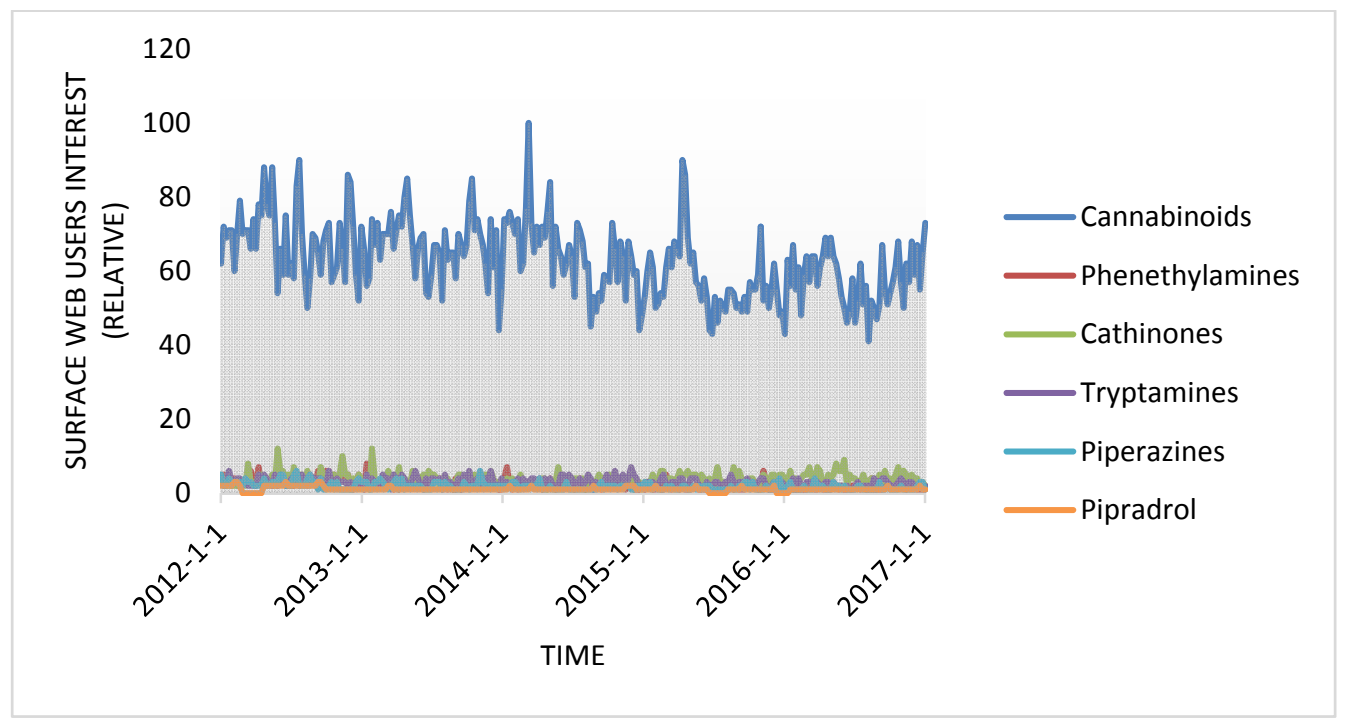

Figure 4. Google Trends (2012-2016): Major Chemical Categories of NPS (worldwide)

The temporal change (year by year) in the trends for each of the category of NPS, appeared to be highly erratic and unsettled for the period 2012-2016 (Figure 5). Synthetic cannabinoids appeared highly oscillating (saw-tooth patterns) with an exception for the transition from; 2012 to 2013 ( $p$-value $=0.254$ ), 2013 to 2014 ( $\mathrm{p}=0.265$ ), and 2015 to 2016 ( $\mathrm{p}=0.624)$. The trends for phenethylamines were also unstable except for the transition from; 2013 to 2014 ( $\mathrm{p}=0.293$ ), and 2015 to 2016 ( $\mathrm{p}=0.241$ ). On the other hand, both cathinones and tryptamines had more steady trends. Piperazine appeared to have oscillating trends for the period 2012 to 2015 with a subsequent steadiness till the end of 2016. Similarly, Pipradol oscillated up and down with an exception for the transition from; 2013 to 2014 ( $\mathrm{p}=0.083), 2013$ to $2016(\mathrm{p}=0.412)$, and 2015 to $2016(\mathrm{p}=0.155)$.

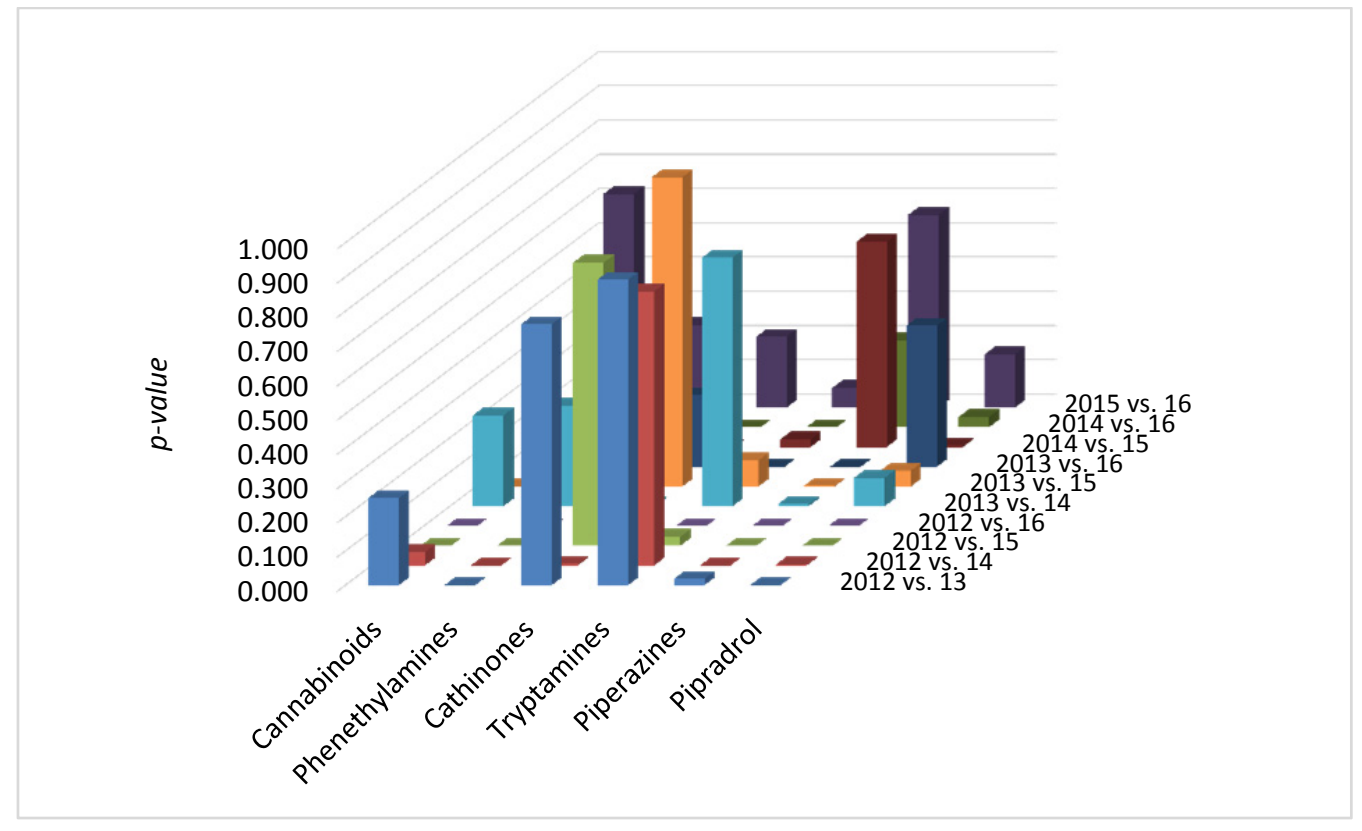

Figure 5. Change in Trends (2012-2016) of the Major Chemical Categories of NPS (worldwide)

The cannabinoids have been more popular than all other categories of NPS (Figure 6) for each year for the period from the beginning of 2012 to the definite end of 2016. Similarly, there were significant differences in between phenethylamines and the other chemical categories of NPS (Figure 7) with an exception for; Phenethylamines versus Cathinones in 2012 ( $p$-value $=0.260)$, Phenethylamines versus Tryptamines in $2012(p=0129)$ and 2013 $(\mathrm{p}=0.060)$, and Phenethylamines versus Piperazines in $2015(\mathrm{p}=0.098)$ and $2016(\mathrm{p}=0.279)$. Cathinones were also more popular than each of piperazine and pipradol groups for all the years (Figure 8) except for Cathinones versus 
Tryptamines in 2014 ( $\mathrm{p}=0.283$ ). The trends of all the remaining three categories of NPS, specifically tryptamines, piperazines, and pipradol were all significantly different from each other (2012-2016).

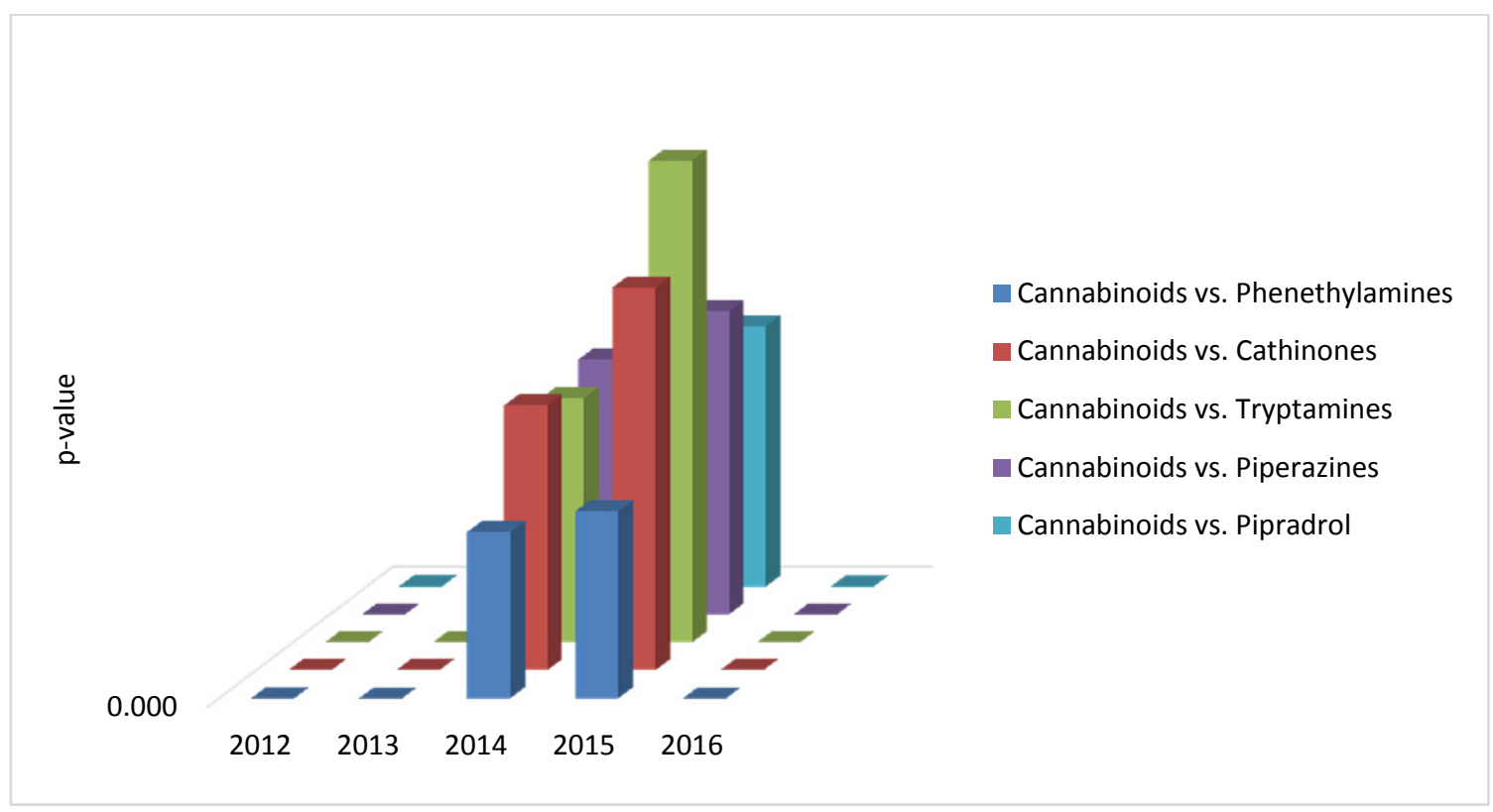

Figure 6. Inferential Statistics: Cannabinoids vs. Other Chemical Categories of NPS (worldwide)

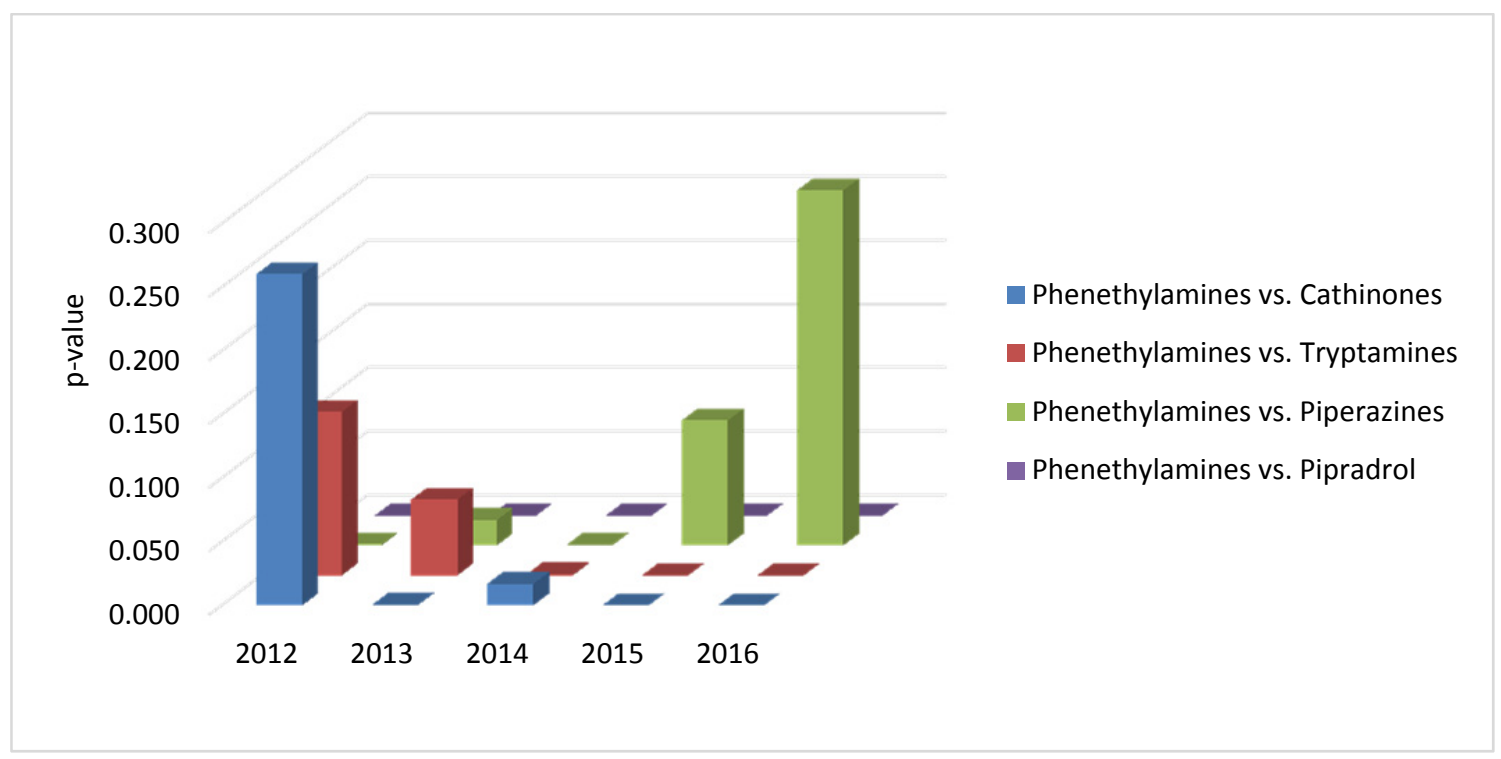

Figure 7. Inferential Statistics: Phenethylamines vs. Other Chemical Categories of NPS (worldwide) 


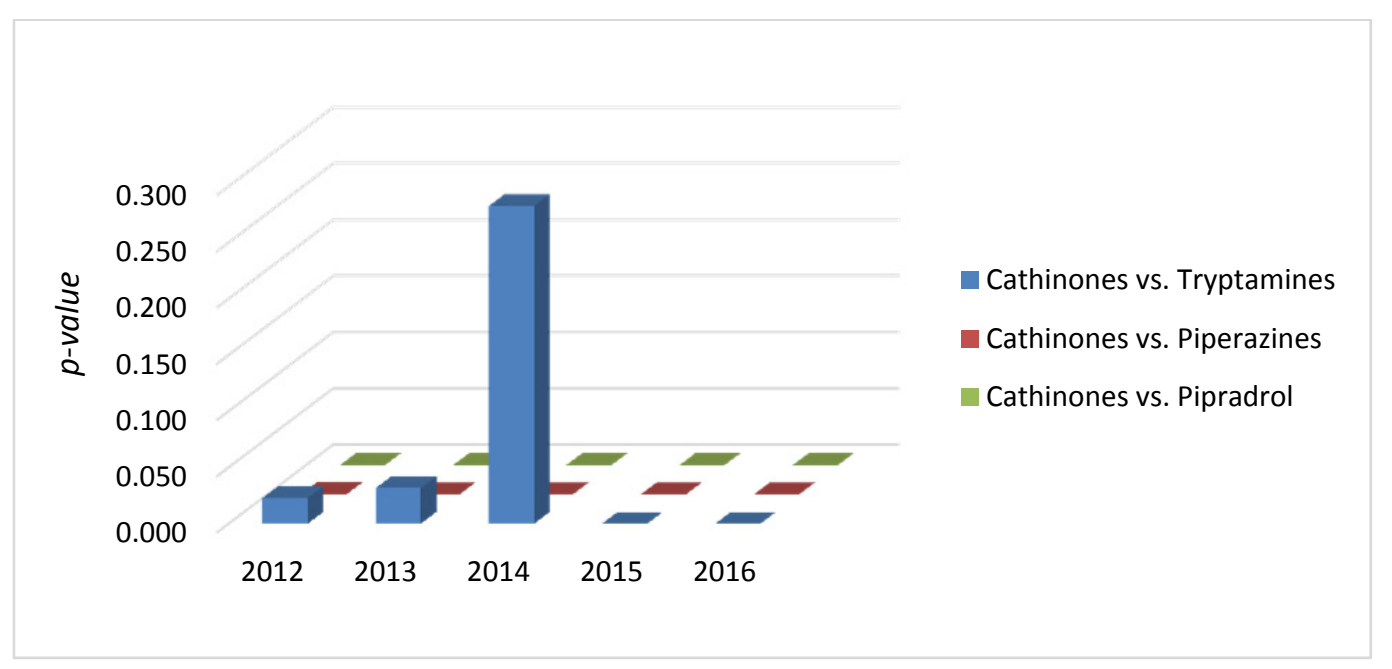

Figure 8. Inferential Statistics: Cathinones vs. Other Chemical Categories of NPS (worldwide)

Trends in the United States (Figure 9) appeared to be consistent with the oscillating global patterns. Top related queries by web users included; synthetic cathinones, cannabinoids breast milk, cannabinoids in breast milk, cbd, cannabinoids and cancer, synthetic marijuana, what is cannabis, what are cannabinoids, synthetic cannabinoids for sale, cannabinoids cancer, what is cannabinoids, and cannabis. Interest in cannabinoids peaked in May 2012 and March 2014, while the highest interest in cathinones was recorded on; June 2012, April 2015, February 2016, and October 2016. Other patterns (inferential) were concordant to a high degree (Figure 10) with the global trends. ANOVA test confirmed that cannabis and cannabinoids are in the lead $(p$-value $<0.001)$ over all other chemical categories of NPS.

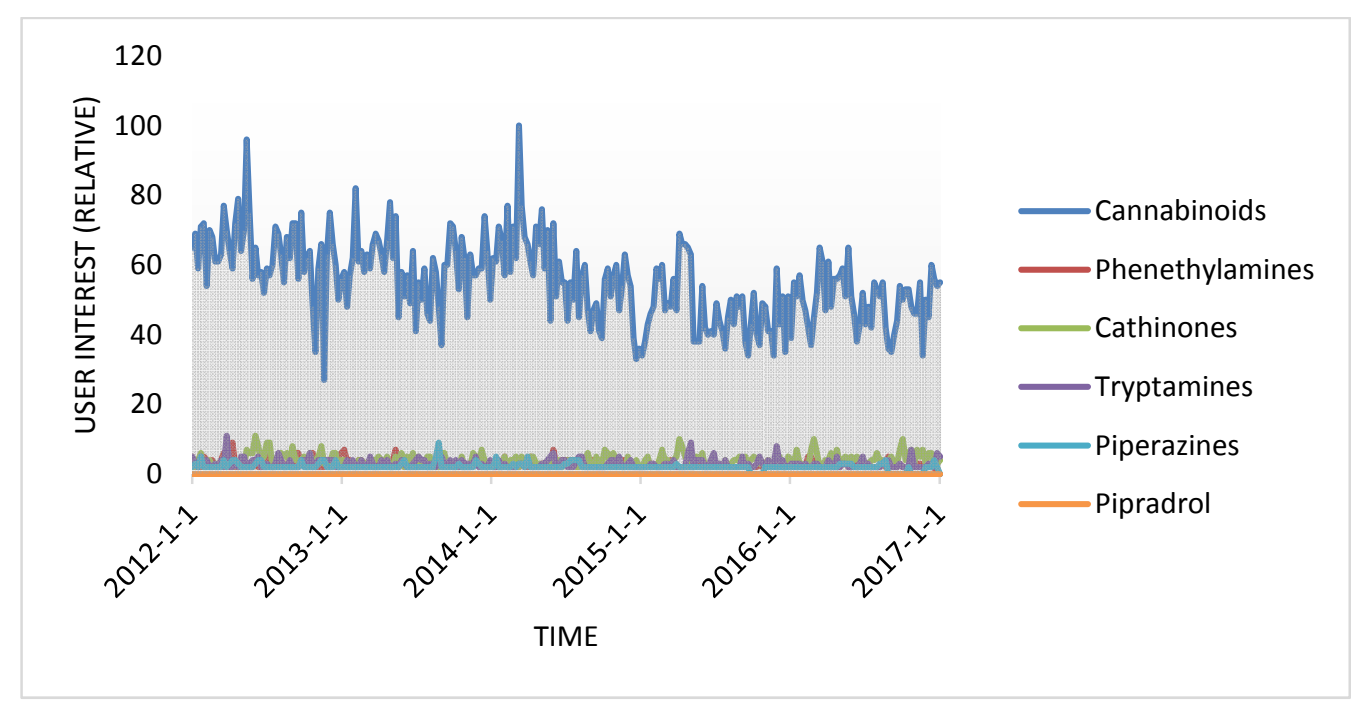

Figure 9. Google Trends (2012-2016): Major Chemical Categories of NPS (United States) 


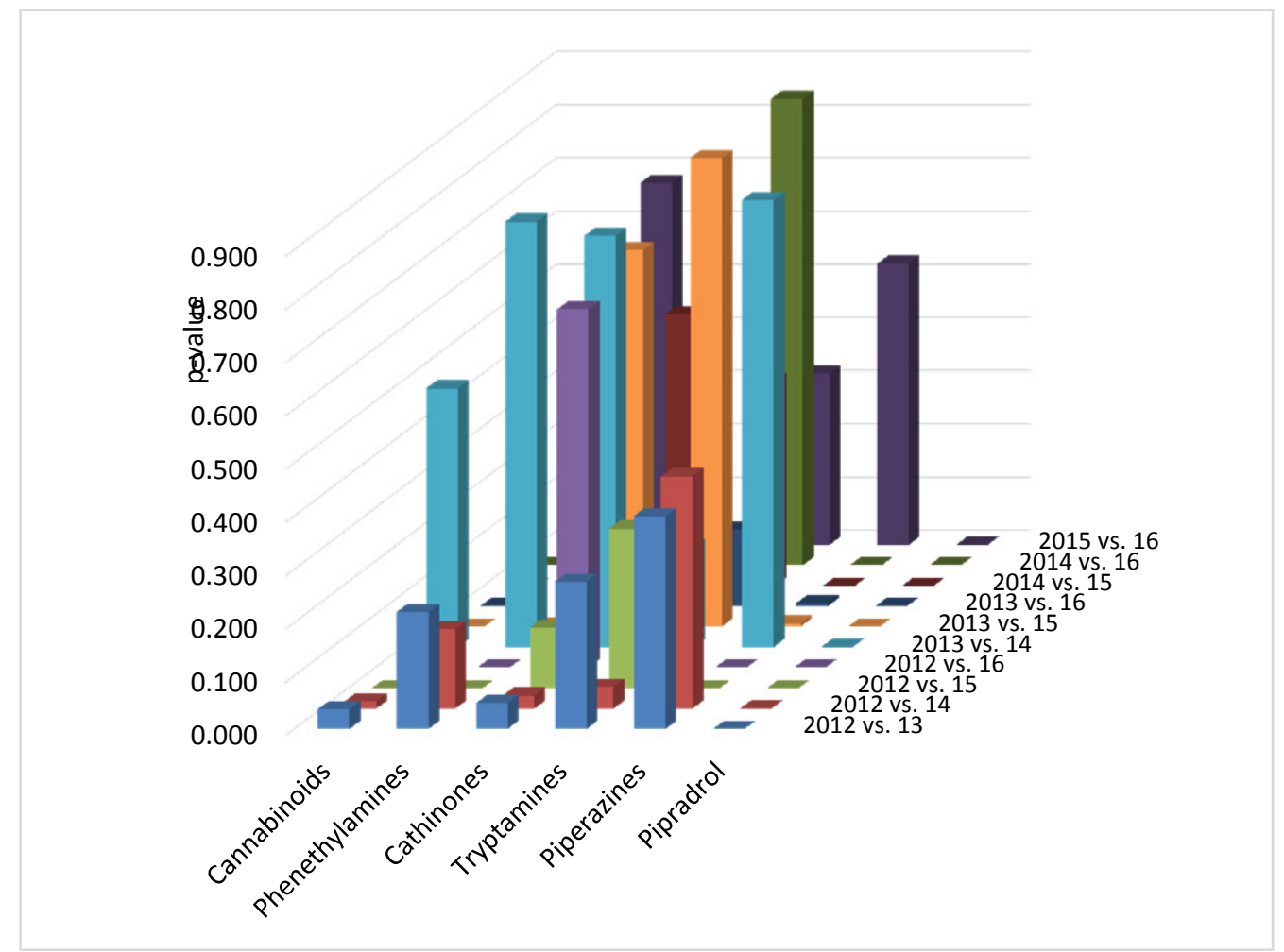

Figure 10. Inferential Statistics: Change in Trends (2012-2016) (United States)

In the United Kingdom (Figures 11), the temporal patterns seem to be distinct from that in the US. However, cannabinoids persist to be the most popular ( $p$-value $<0.001)$ while other categories of NPS were in close competition with each other. Interest in cannabinoids reached a maximum in December 2014 (different from the US patterns), while cathinones achieved the highest peaks in December 2013, and August 2015 (also distinct from the US). The only related query by web users was the term synthetic cannabinoids. Results of inferential statistics are visualised in Figure 12.

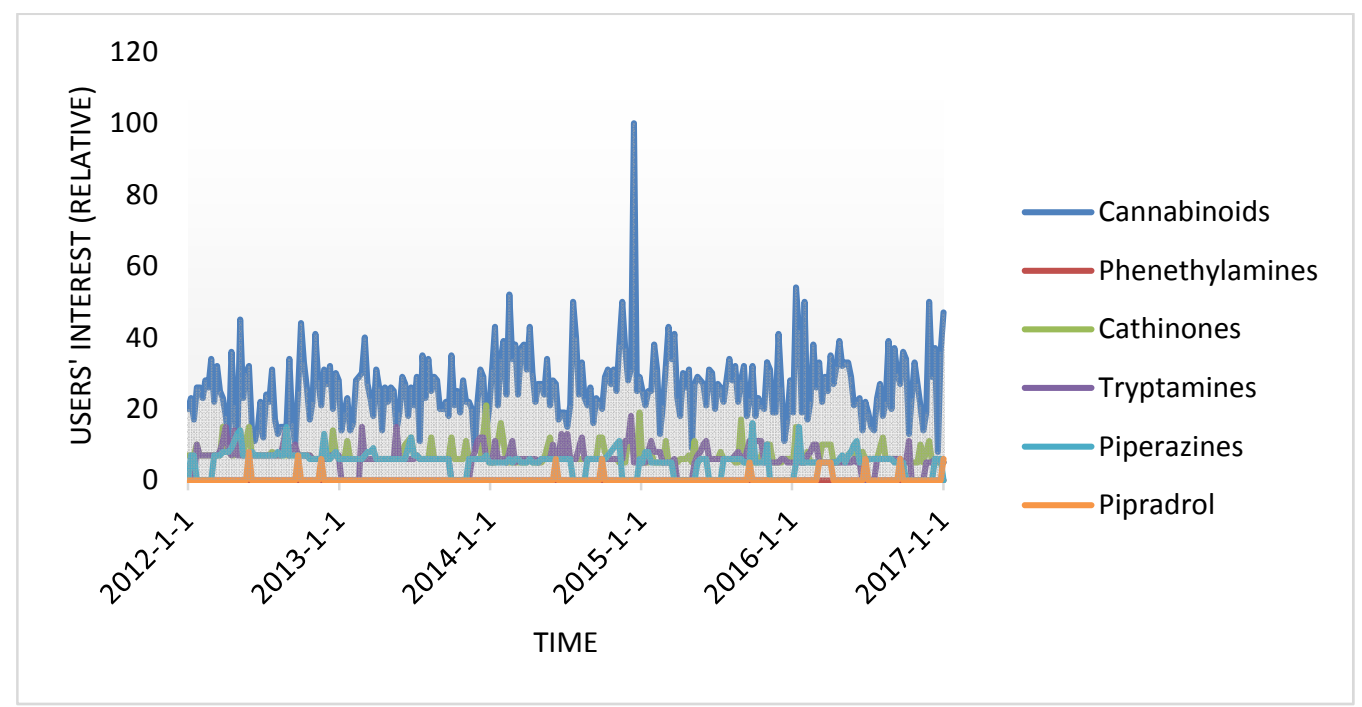

Figure 11. Google Trends (2012-2016): Interest in Chemical Categories of NPS (United Kingdom) 


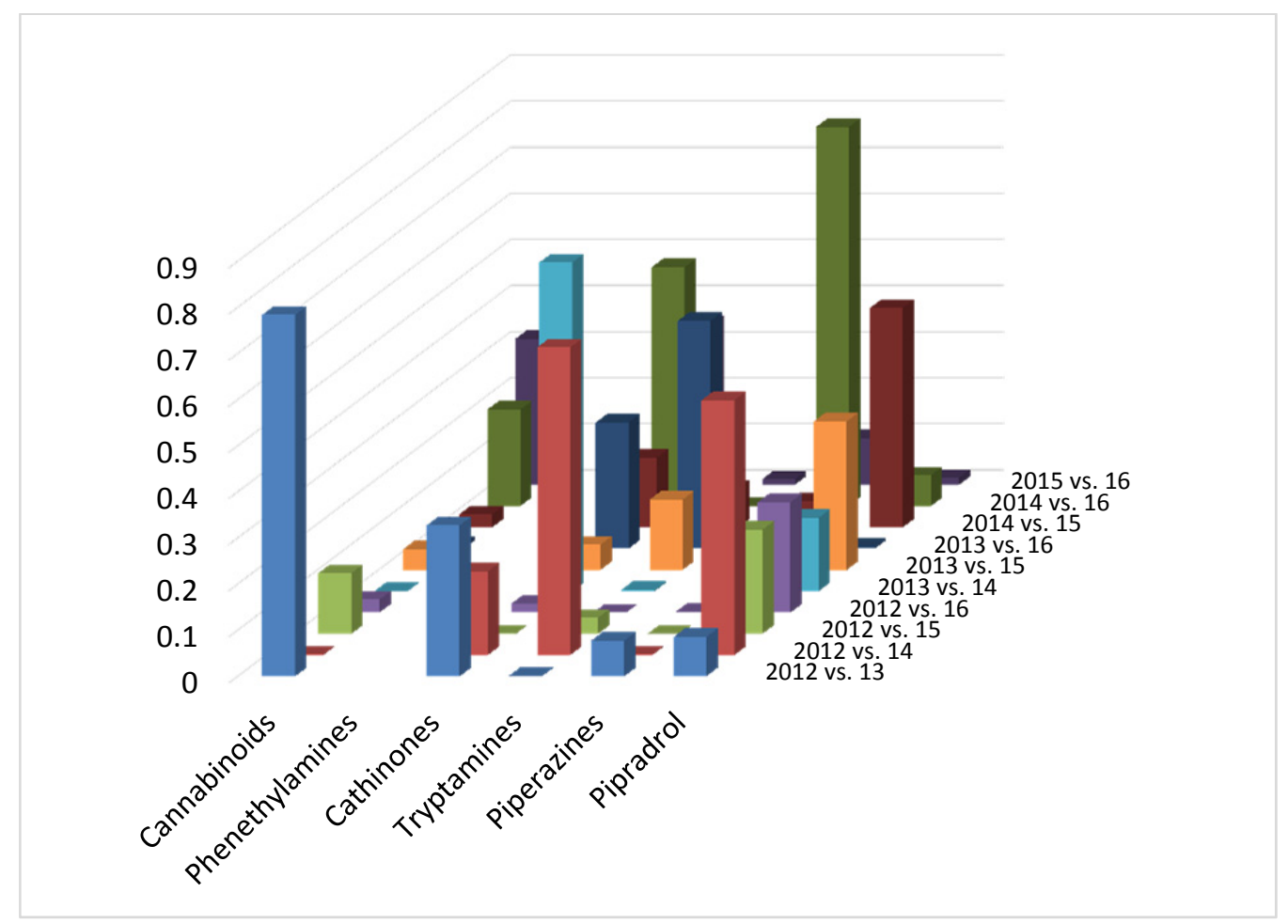

Figure 12. Inferential Statistics for Change in Trends (2012-2016) (United Kingdom)

In Canada, the patterns (trends) were also novel from those seen in the US or the UK. However, both cannabinoids $\left(\right.$ rank $1^{\text {st }}$ ) and cathinones $\left(\right.$ rank $\left.2^{\text {nd }}\right)$ persisted to be the most popular. Top related queries were not accessible from the database. Interest in cannabinoids peaked in April-May 2012, January 2015, March 2015, and July 2016 (Figure 13), while interest in cathinones reached highest levels in May-June 2012, and June 2014. Furthermore, it seems that the Canadian citizens were not interested in other forms of NPS including phenethylamines, tryptamines, piperazines, and pipradrol. The inferential statistics also confirmed that cannabis and cannabinoids were more popular than cathinones for the entire period 2012-2016 (p-value $<0.001)$.

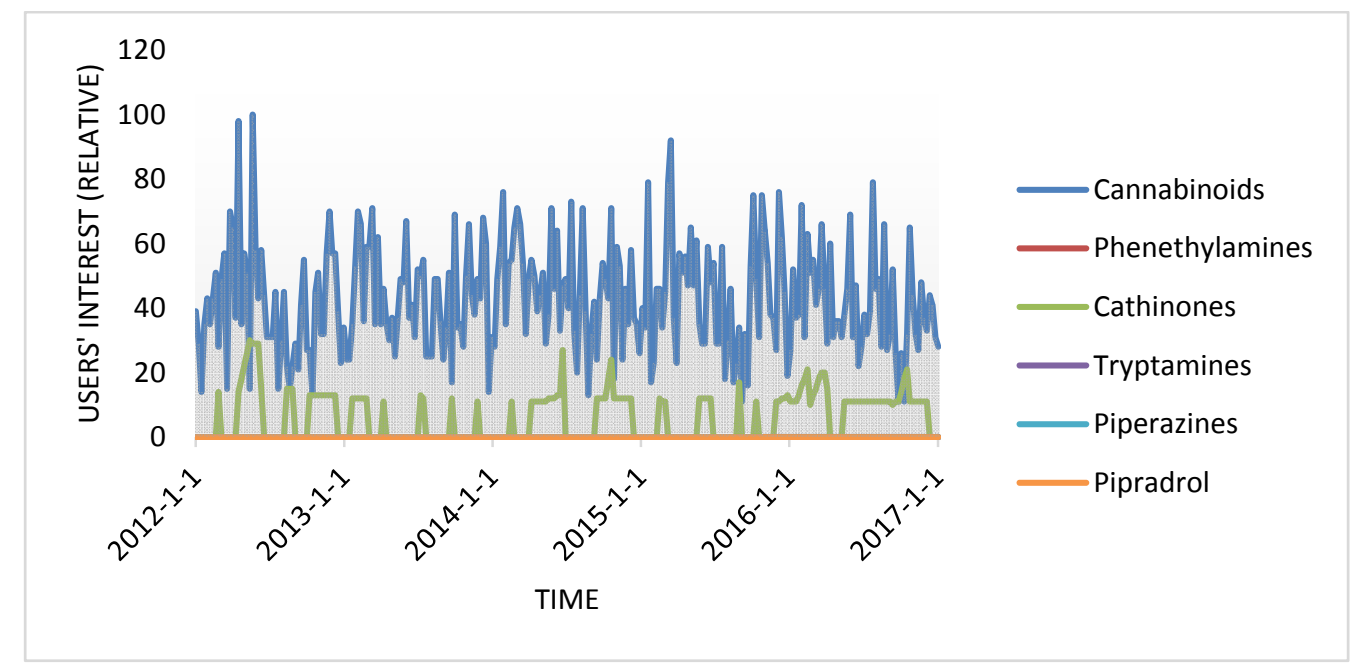

Figure 13. Google Trends (2012-2016): Interest in Chemical Categories of NPS (Canada)

In Australia, the trends of surface web users' interest seem to be somehow comparable to that of Canada, Australian citizens were highly interested in cannabinoids ( $\operatorname{rank} 1^{\text {st }}$ ) and cathinones (rank $2^{\text {nd }}$ ), and they appear to be not interested in other categories (Figure 14). Attentiveness towards cannabinoids was maximum in February 
2012, while cathinones peaked in April 2015. Top related queries on that database included only "synthetic cannabinoids". Inferential statistics revealed that cannabis and cannabinoids were also the most popular $(\mathrm{p}<0.001)$.

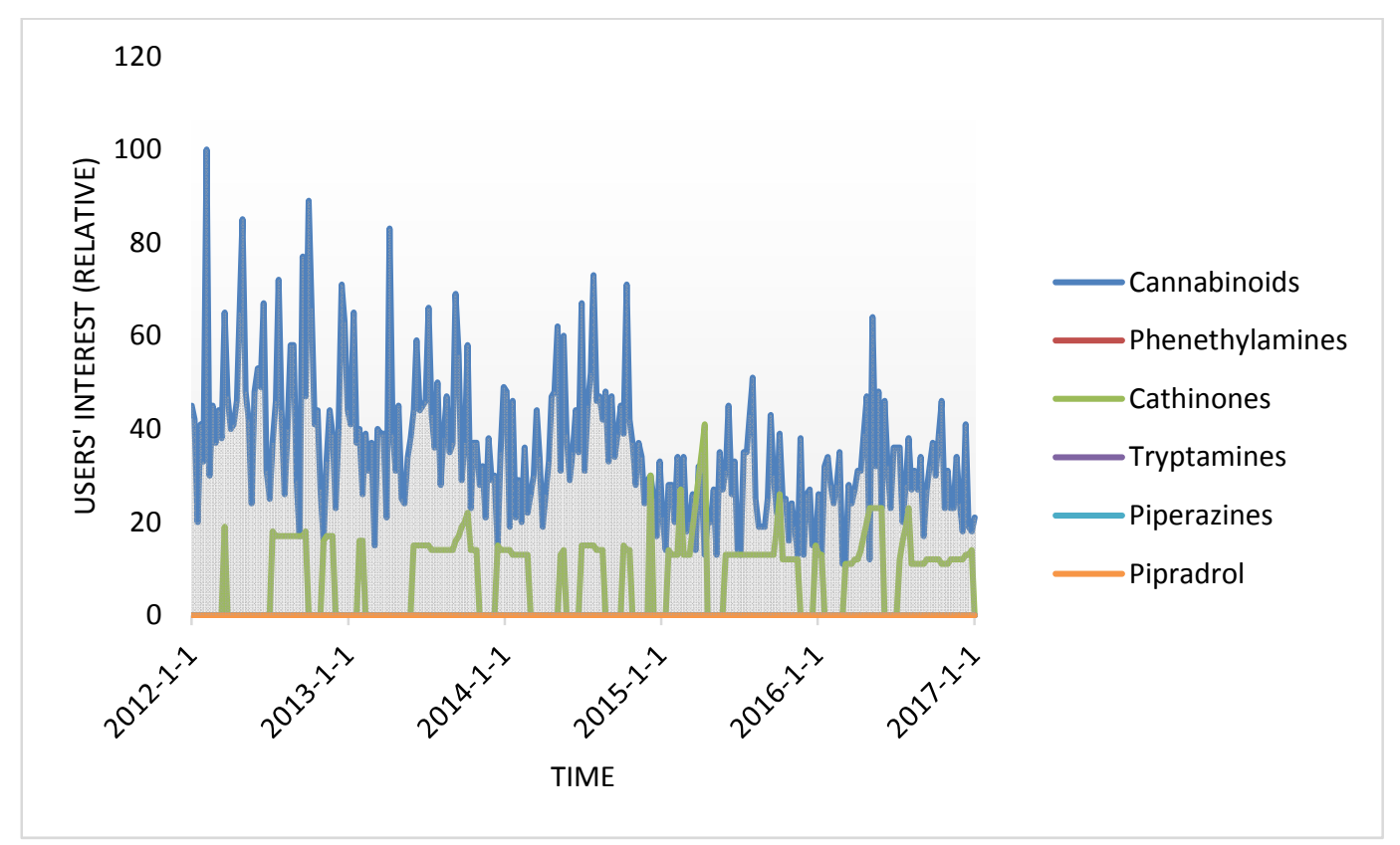

Figure 14. Google Trends (2012-2016): Interest in Chemical Categories of NPS (Australia)

The repeated pattern in which cannabis and cannabinoids were ahead in the competition over all other types of NPS, was consistent with trending pattern on the representative darknet e-marketplace of the deep web (Figure 15). Based on cross-sectional and longitudinal analyses from prior studies, cannabinoids and cannabimimetic were also of high prevalence in Iraq (Al-Hemiary et al., 2014; Al-Hemiary et al., 2017). However, Middle Eastern and Arabic Countries did not contribute, by any means, to the e-trends on the surface web as observed via Google Trends database. Furthermore, geolocation confirmed the presence of only four countries; all of which are from the developed western world. This pattern was also in harmony in relation to the minor contribution of the Middle Eastern and Arabic countries on the deep web. 


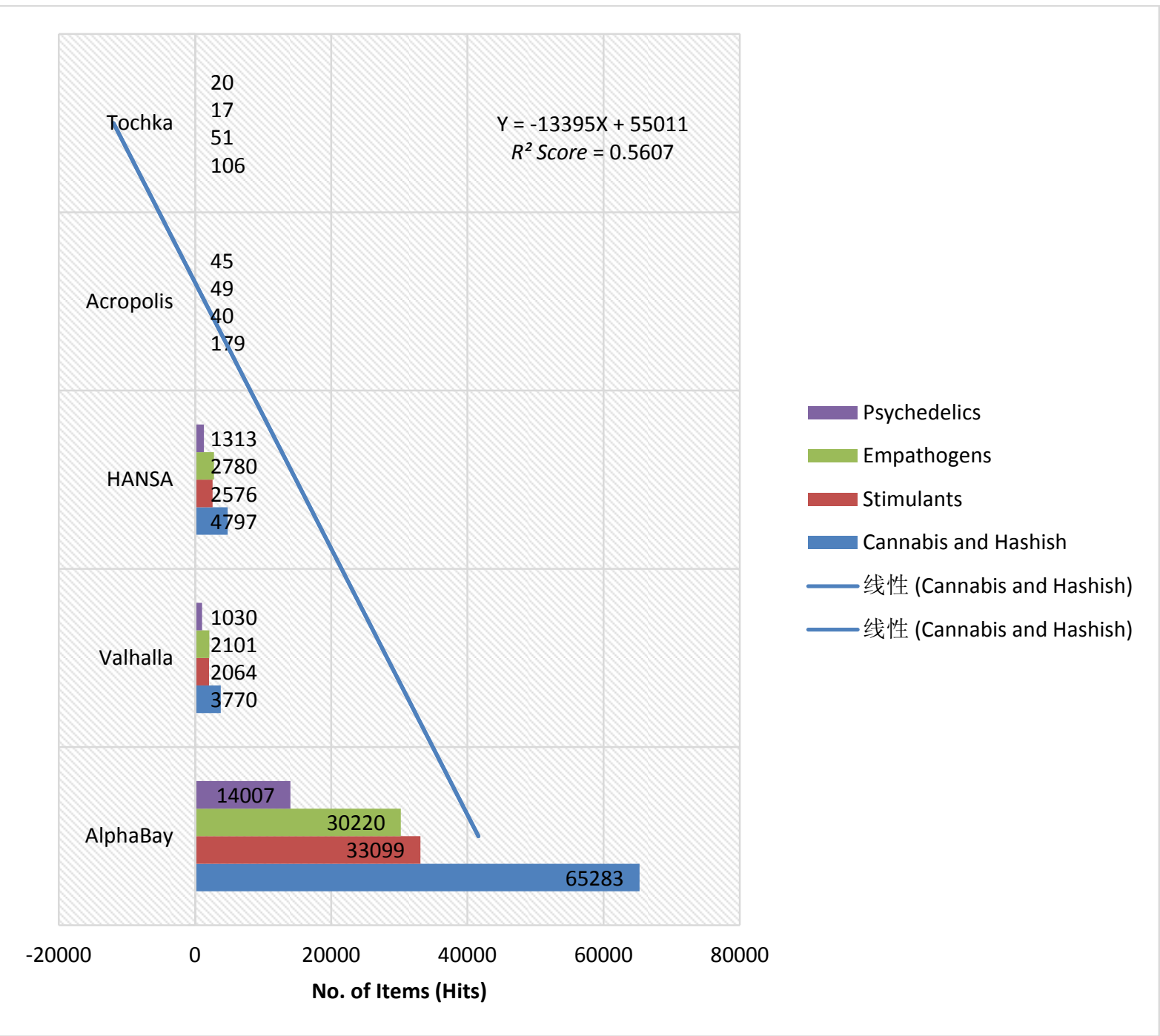

Figure 15. Most Popular Chemical Categories of NPS on the e-markets of the Darknet

To re-encapsulate, the phenomenon of NPS seems to be affecting the developed world to a greater extent; the threats are not limited to jeopardizing the public health, but also the economy and even the security of nations and societies in connection with extremism and terrorism (Al-Imam et al., 2016; Al-Imam, 2017; Al-Imam et al., 2017). The high attentiveness of residents of the US towards cannabis and cannabimimetic substances can be partially explained by the fact that marijuana (cannabis) is considered legal in several states in the US.

Within the discipline of NPS research, upgrades and enhancements should be deployed at these front lines; augmenting the quality and quantity of studies in developed as well as the poorly-mapped developing countries including Middle Eastern and Arabic countries in the North of Africa (1), incorporation of efficient use of data science and advanced web analytics (2), compulsory training in information science, biostatistics, and basic neuroscience for all NPS researchers, chemists, and toxicologists (3), integration of social science methodologies (4), validation and incorporation of data mining technologies and real-time analyses (5), inclusion of the rarely-used experimental studies including quasi-experiments, randomized controlled trials (RCTs), pragmatic RCTs, and animal modelling (6), enhancement and potentiation of internet snapshot techniques (7), implementation of comparative chemical analyses and characterization of the trending NPS (8), and the full exploitation of trends databases of the surface web (9). Perhaps, the integration of real-time data mining and data crunching will represent the climax armament to antagonise the alarming e-trade phenomenon.

\section{Conclusion}

Data describing the attentiveness (interest) of surface web users towards a particular category of NPS appears to be restrictively originating from four countries; the US, the UK, Canada, Australia. In each of these developed 
countries, the user attentiveness is highly oscillating for the period from 2012 to 2016 . However, there are some fixed norms; cannabinoids seem to be the most popular category of NPS, while cathinones are ranked $2^{\text {nd }}$, particularly in the US. Meanwhile, other NPS are in fierce competition with each other. In Canada and Australia, the pattern is indistinguishable with the exception that nothing can be inferred about categories of NPS other than cannabinoids $\left(\operatorname{rank} 1^{\text {st }}\right.$ ) and cathinones $\left(\operatorname{rank} 2^{\text {nd }}\right)$. It has been concluded that the trends in the US are steering the global NPS trends. The trends were found to be in disharmony as an observer goes from the US to the UK, and from the UK to each of Australia and Canada. Data from Google Trends database gave a predictive inference to the expected analogue patterns on the deep web. One limitation of this study is the absence of data from other regions of the world including the developing countries, Arabic countries, or the densely populated parts of the world. A critical application of an excellent value is the use of data mining techniques to generate real-time inferences in connection with the trends databases.

\section{Competing Interests Statement}

The authors declare that they have no competing or potential conflicts of interest.

\section{Source of Funding}

This study was entirely self-funded.

\section{References}

Al-Hemiary, N. J., Al-Diwan, J. K., Hasson, A. L., \& Rawson, R. A. (2014). Drug and alcohol use in Iraq: findings of the inaugural Iraqi Community Epidemiological Workgroup. Substance use \& misuse, 49(13), 1759-1763. https://doi.org/10.3109/10826084.2014.913633

Al - Hemiery, N., Dabbagh, R., Hashim, M. T., Al - Hasnawi, S., Abutiheen, A., Abdulghani, E. A., ... \& Brecht, M. L. (2017). Self - reported substance use in Iraq: findings from the Iraqi National Household Survey of Alcohol and Drug Use, 2014. Addiction. https://doi.org/10.1111/add.13800

Burchardt, H., Serafimovski, N., Tsonev, D., Videv, S., \& Haas, H. (2014). VLC: Beyond point-to-point $\begin{array}{llll}\text { communication. IEEE Communications } & \text { Magazine, }\end{array}$ https://doi.org/10.1109/MCOM.2014.6852089

Al-Imam, A. (2017). Could Hallucinogens Induce Permanent Pupillary Changes in (Ab) users? A Case Report from New Zealand. Case Reports in Neurological Medicine, 2017. https://doi.org/10.1155/2017/2503762

Al-Imam, A., Santacroce, R., Roman - Urrestarazu, A., Chilcott, R., Bersani, G., Martinotti, G., \& Corazza, O. (2017). Captagon: use and trade in the Middle East. Human Psychopharmacology: Clinical and Experimental, $32(3)$.

Al-Imam, A., Simonato, A. P., \& Corazza, O. (2016). Haloperidol, an old antipsychotic with potential use by NPS users in Iraq. Research and Advances in Psychiatry, 3(3), 81-84. Retrieved from https://www.rapjournal.eu/materiale_cic/948_3_3/8031_haloperidol/article.htm

Dargan, P., \& Wood, D. (Eds.). (2013). Novel psychoactive substances: classification, pharmacology and toxicology. Academic Press.

Emcdda, E. (2013). New drugs in Europe 2012: EMCDDA-Europol 2012 annual report on the implementation of Council Decision 2005/387/JHA. Luxembourg: Publications Office of the European Union.

Fan, W., \& Bifet, A. (2013). Mining big data: current status, and forecast to the future. ACM sIGKDD Explorations Newsletter, 14(2), 1-5. https://doi.org/10.1145/2481244.2481246

Fettweis, G. P. (2014). The tactile internet: Applications and challenges. IEEE Vehicular Technology Magazine, 9(1), 64-70. https://doi.org/10.1109/MVT.2013.2295069

Google. Google Trends. Retrieved 28 February, 2017, from https://trends.google.com/trends/

Google. Google Trends. Retrieved $28 \quad$ February, 2017, from https://trends.google.com/trends/explore?date=2012-01-01\%202017-01-01\&q=Phenethylamines, Tryptamin es,Piperazines, Cathinones, Cannabinoids

Google. Google Trends. $\quad$ Retrieved $28 \quad$ February, 2017, from https://trends.google.com/trends/explore?date=2012-01-01\%202017-01-01\&geo=US\&q=Phenethylamines, Tryptamines,Piperazines, Cathinones, Cannabinoids.

Google. Google Trends. Retrieved $28 \quad$ February, 2017, from https://trends.google.com/trends/explore?date=2012-01-01\%202017-01-01\&geo=GB\&q=Phenethylamines, 
Tryptamines,Piperazines,Cathinones,Cannabinoids.

Google. Google Trends. Retrieved $28 \quad$ February, 2017, from https://trends.google.com/trends/explore?date=2012-01-01\%202017-01-01\&geo=AU\&q=Phenethylamines, Tryptamines,Piperazines, Cathinones,Cannabinoids.

Griffiths, P., Evans - Brown, M., \& Sedefov, R. (2014). The (mis) use of psychoactive medicines: Getting the balance right in complex systems. Addiction, 109(2), 182-183. https://doi.org/10.1111/add.12306

Jha, N. K., Jethva, A., Parmar, N., \& Patil, A. (2016). A Review Paper on Deep Web Data Extraction using WordNet.

Larose, D. T. (2014). Discovering knowledge in data: an introduction to data mining. John Wiley \& Sons. https://doi.org/10.1002/9781118874059

Lederman, A. (2016). Google Just Gets to the Tip of the Iceberg: How to Get to the Gems in the Deep Web. Refer, $32(2), 16$.

Lee, V., \& Wei, H. (2016, June). Exploratory simulation models for fraudulent detection in Bitcoin system. In Industrial Electronics and Applications (ICIEA), 2016 IEEE 11th Conference on (pp. 1972-1977). IEEE. https://doi.org/10.1109/ICIEA.2016.7603912

Miranda Palacios, B. E. (2014). Surface Web vs. Deep Web. Revista de Información, Tecnología y Sociedad, 14.

O'Rourke IV, J. S., Harris, B., \& Ogilvy, A. (2007). Google in China: government censorship and corporate reputation. Journal of Business Strategy, 28(3), 12-22. https://doi.org/10.1108/02756660710746229

Reid, F., \& Harrigan, M. (2013). An analysis of anonymity in the bitcoin system. In Security and privacy in social networks (pp. 197-223). Springer New York. https://doi.org/10.1007/978-1-4614-4139-7_10

Rolles, S., \& Kushlick, D. (2014). Prohibition is a key driver of the new psychoactive substances (NPS) phenomenon. Addiction, 109(10), 1589-1590. https://doi.org/10.1111/add.12543

Rudesill, D. S., Caverlee, J., \& Sui, D. (2015). The Deep Web and the Darknet: A Look Inside the Internet's Massive Black Box.

Saniotis, A. (2010). Evolutionary and anthropological approaches towards understanding human need for psychotropic and mood altering substances. Journal of psychoactive drugs, 42(4), 477-484. https://doi.org/10.1080/02791072.2010.10400710

Stevens, C. E., Xie, E., \& Peng, M. W. (2016). Toward a legitimacy - based view of political risk: The case of Google and Yahoo in China. Strategic Management Journal, 37(5), 945-963. https://doi.org/10.1002/smj.2369

Thompson, C. (2006). Google's China problem (and China's Google problem). The New York Times, 23.

Tracy, D. K., Wood, D. M., \& Baumeister, D. (2017). Novel psychoactive substances: types, mechanisms of action, and effects. $b m j$, 356, i6848. https://doi.org/10.1136/bmj.i6848

Van Hout, M. C., \& Bingham, T. (2013). 'Surfing the Silk Road': A study of users' experiences. International Journal of Drug Policy, 24(6), 524-529. https://doi.org/10.1016/j.drugpo.2013.08.011

Van Hout, M. C., \& Bingham, T. (2014). Responsible vendors, intelligent consumers: Silk Road, the online revolution in drug trading. International Journal of Drug Policy, 25(2), 183-189. https://doi.org/10.1016/j.drugpo.2013.10.009

Webster, F. (2014). Theories of the information society. Routledge.

Wu, X., Zhu, X., Wu, G. Q., \& Ding, W. (2014). Data mining with big data. IEEE transactions on knowledge and data engineering, 26(1), 97-107. https://doi.org/10.1109/TKDE.2013.109

\section{Copyrights}

Copyright for this article is retained by the author(s), with first publication rights granted to the journal.

This is an open-access article distributed under the terms and conditions of the Creative Commons Attribution license (http://creativecommons.org/licenses/by/4.0/). 